\title{
EFEITOS DA PURIFICAÇÃO E DO ENRIQUECIMENTO DO CREOSOTO VEGETAL NA PRESERVAÇÃO DA MADEIRA DE Eucalyptus grandis, APÓS 48 MESES DE INSTALAÇÃO DO ENSAIO DE CAMPO ${ }^{1}$
}

Juarez Benigno Paes ${ }^{2}$, Benedito Rocha Vital ${ }^{3}$, Ricardo Marius Della Lucia ${ }^{3}$ e Terezinha Maria Castro Della Lucia ${ }^{4}$

\begin{abstract}
RESUMO - O objetivo deste trabalho foi avaliar a eficiência da purificação e do enriquecimento do creosoto vegetal contra xilófagos, após 48 meses de instalação do ensaio de campo. Por destilação do alcatrão vegetal, obteve-se o creosoto vegetal bruto (creosoto 1), recuperado à temperatura de $110-255^{\circ} \mathrm{C}$. Uma fração dos destilados foi lavada com solução a $9 \%$ de bicarbonato de sódio, para obter o creosoto vegetal purificado (creosoto 2). Os creosotos 1 e 2 foram enriquecidos com 3\% de naftenato de cobre; 3\% de naftenato de zinco; $3 \%$ de naftenato de cobalto; $2 \%$ de TBTO; $2 \%$ de tribromofenato de tributil-estanho; $2 \%$ de pentaclorofenol; ou $0,4 \%$ de trióxido de arsênico. Estacas obtidas do alburno de Eucalyptus grandis foram tratadas pelo processo de célula cheia. A eficiência das soluções de creosoto vegetal foi comparada com a do creosoto mineral. O ensaio foi instalado em três localidades (Viçosa, Ponte Nova e Leopoldina). Os resultados indicam que o creosoto $2+$ pentaclorofenol foi superior aos creosotos 1 e $2+$ TBTO, aos creosotos 1 e $2+$ naftenato de zinco e ao creosoto 1 puro, sendo semelhante ao creosoto mineral. O creosoto 2 foi superior ao creosoto 1 apenas para a localidade de Leopoldina. De modo geral, a vida média da madeira não-tratada ficou entre 12 e 24 meses, a da madeira tratada com o creosoto 1 + TBTO entre 24 e 37 meses e a da tratada com o creosoto 1 + naftenato de zinco entre 37 e 48 meses e a com o creosoto $1+$ naftenato de cobalto, creosoto 2 puro e creosoto $2+$ naftenato de zinco ou TBTO foi de 48 meses. No atual estágio da pesquisa, não é possível estimar a vida média da madeira tratada com as demais soluções preservativas testadas, pois ainda não atingiram os $60 \%$ das estacas quebradas.
\end{abstract}

Palavras-chave: Creosoto vegetal, preservativos de madeira e ensaio de campo.

\section{EFFECTS OF THE PURIFICATION AND ENRICHMENT OF WOOD TAR CREOSOTE ON PRESERVATION OF Eucalyptus grandis WOOD, AFTER 48 MONTHS OF FIELD TESTING}

\begin{abstract}
The objective of this work was to evaluate the efficiency of purifying and enriching wood tar creosote against wood decay after 48 months in field testing. By distillation of wood tar, the crude wood tar (creosote 1) was recovered at a temperature of $110-255^{\circ} \mathrm{C}$. A fraction of the distilled was washed with a solution of sodium bicarbonate at $9 \%$, resulting in purified wood tar creosote (creosote 2). Creosotes 1 and 2 were enriched with 3\% copper naphtenate; 3\% zinc naphtenate; 3\% of cobalt naphtenate; 2\% TBTO; 2\% tributil-tin tribromophenate; $2 \%$ pentachlorophenol; or $0.4 \%$ arsenic trioxide. Stakes of Eucalyptus grandis sapwood were treated by following the full cell process. The efficiency of wood tar creosote solutions was compared with that of coal tar creosote. The essay was established in three locations (Viçosa, Ponte Nova and Leopoldina -Minas Gerais, Brazil). The results showed that creosote $2+$ pentaclorofenol was superior to creosotes 1 and $2+T B T O$, to creosotes 1 and $2+$ zinc naftenato and to pure creosote 1, being similar to coal tar creosote. Creosote 2 was superior to creosote 1, only in Leopoldina. In general, the average life of untreated wood was between 12 and 24 months. The average life of wood treated with creosote $1+T B T O$ was between 24 and 37 months, while that of
\end{abstract}

1 Recebido para publicação em 10.7.2001.

Aceito para publicação em 20.6.2002.

2 Dep. de Engenharia Florestal da Universidade Federal de Pernambuco - UFPB, 58700-970 Patos-PB, <jbp2@uol.com.br>.

${ }^{3}$ Dep. de Engenharia Florestal da Universidade Federal de Viçosa - UFV, 36571-000 Viçosa-MG; ${ }^{4}$ Dep. de Biologia Animal da UFV. 
wood treated with creosote $1+$ zinc naftenato, between 37 and 48 months and that of wood treated with creosote $1+$ cobalt naftenato, pure creosote 2, creosote $2+$ zinc naftenato or + TBTO was 48 months. At this stage of research it is not possible to estimate the treated wood average life, as compared with the other tested preservative solutions, it since $60 \%$ of the stakes did not break.

Key words: $\quad$ Wood tar creosote, wood preservatives and field testing.

\section{INTRODUÇÃO}

A primeira tentativa de evitar a deterioração da madeira pelo emprego de substâncias químicas foi por meio da imersão das peças em uma mistura de alcatrão vegetal e ácidos pirolenhosos (Wenzl, 1970; Richardson, 1993). Assim, o alcatrão de madeira é o mais antigo dos produtos preservativos conhecidos pela humanidade (Van Groenov et al., 1952; Jankowsky, 1986b, Lepage, 1986; Richardson, 1993).

Por meio da destilação do alcatrão é obtido o creosoto vegetal. Este, no entanto, não se firmou como produto para o tratamento de madeiras, pois sua produção era insuficiente para atender aos interesses dos grandes consumidores de creosoto (Blew \& Champion, 1952, 1965; Hunt \& Garratt, 1967). Assim, a utilização do creosoto vegetal para preservação de madeiras foi interrompida no início do século XX, ao mesmo tempo em que os esforços de pesquisa concentraram-se no creosoto mineral e nos preservativos hidrossolúveis (Jankowsky, 1986a). O emprego extensivo do creosoto vegetal foi também prejudicado pela variabilidade na sua composição (Blew \& Champion, 1952, 1965; Hunt \& Garratt, 1967). A produção insuficiente para uso na impregnação de madeiras devia-se, provavelmente, a outras oportunidades de mercado, tanto para o creosoto como para o alcatrão. A variabilidade na composição refletia a falta de uma especificação ou norma técnica exclusiva para o creosoto destinado à impregnação de madeiras.

Mesmo com tais restrições diversas marcas de creosoto vegetal, destinado à preservação de madeiras, eram comercializadas no início do século XX, nos Estados Unidos e em vários países da Europa (Jankowsky, 1986a).

De acordo com Wilkinson (1979), o creosoto vegetal é utilizado apenas em países com deficiências no suprimento de creosoto mineral, pois como preservativo para madeiras ele é um produto de pequena importância. Mesmo assim, as características preservativas do creosoto vegetal, em virtude do alto teor de fenóis, têm sido objeto de estudos constantes.

R. Árvore, Viçosa-MG, v.26, n.4, p.475-484, 2002
O creosoto vegetal, em virtude de seu caráter fenólico, é eficiente contra fungos e insetos xilófagos. É um produto obtido de fonte renovável, mas que atualmente não é utilizado para o tratamento de madeiras, principalmente por falta de pesquisas que visem melhorias nas suas características preservativas.

A eficiência do creosoto vegetal tem sido comprovada por várias pesquisas. Mesmo assim, poucos esforços têm sido dispensados com o intuito de destilar um produto de qualidade uniforme, que pudesse se enquadrar em uma normalização técnica (Findlay, 1985). Porém, vários autores constataram que o creosoto vegetal apresenta menor eficiência que o mineral em ensaio de campo (Hunt \& Snyder, 1948; Tiemann, 1951; Van Groenov et al., 1952; Blew \& Johnston, 1956).

Além da disponibilidade e da falta de padronização, os alcatrões de madeira de folhosas possuem caráter ácido. Assim, seus creosotos podem ter conteúdo ácido elevado (Hunt \& Garratt, 1967). A acidez do creosoto vegetal é causada pela presença dos ácidos acético e fórmico, que corroem o ferro e o aço e prejudica o emprego do produto em tratamentos industriais (Hunt \& Garratt, 1967; Jankowsky, 1986 b). Jankowsky (1986 b) relatou que a forma mais viável de resolver o problema é efetuar a retificação do creosoto, visando a neutralização dos ácidos.

O enriquecimento ou a fortificação do creosoto vegetal, e a exemplo do que se pratica para o creosoto mineral, a purificação ou a neutralização dos ácidos do creosoto vegetal poderão trazer grandes benefícios à utilização desse preservativo, pois, por ser o creosoto de madeira menos viscoso que o mineral (Richardson, 1993), ele terá grande penetração na madeira, reduzindo, deste modo, tempos e pressões de tratamento.

O objetivo da pesquisa foi avaliar o efeito da purificação e do enriquecimento do creosoto vegetal contra a deterioração da madeira, após 48 meses de instalação do ensaio de campo. 


\section{MATERIAL E MÉTODOS}

\subsection{Obtenção, Destilação e Purificação do Alcatrão Vegetal}

O alcatrão vegetal utilizado foi produzido pela Companhia Agrícola e Florestal Santa Bárbara (CAF), em Bom Despacho-MG. O produto foi recuperado como subproduto da carbonização das madeiras de Eucalyptus grandis W.Hill ex Maiden e E. cloeziana F. Muell. ( $\pm 50 \%$ de cada espécie).

Para produção das soluções preservativas, o alcatrão foi destilado a temperaturas compreendidas entre $110 \mathrm{e}$ $255^{\circ} \mathrm{C}$, à pressão atmosférica, em retorta de cobre de 201 de capacidade, tendo sido destilados 121 de cada vez. Os vapores da destilação foram condensados por uma bateria de três condensadores "Liebig", ligados em série.

Da destilação do alcatrão, obteve-se o creosoto vegetal bruto (creosoto 1 ). $O$ creosoto vegetal purificado (creosoto 2) foi obtido ao lavar o creosoto 1 com uma solução a 9\% de bicarbonato de sódio.

\subsection{Preparo das Soluções Preservativas}

As soluções de creosoto foram utilizadas puras ou enriquecidas com várias substâncias químicas, para obter as soluções preservativas, que foram utilizadas no tratamento da madeira de Eucalyptus grandis (Quadro 1).

Assim, foram preparadas 16 soluções preservativas, sendo 14 enriquecidas (sete com creosoto 1 e sete com creosoto 2), as quais foram testadas e comparadas a duas testemunhas: uma com madeira de alburno de $E$. grandis tratada com creosoto mineral e outra com a madeira nãotratada.

Os produtos e as concentrações empregadas no enriquecimento dos creosotos 1 e 2 tiveram como base o utilizado para o creosoto mineral, pois por causa da ação de certos xilófagos que apresentam tolerância a esse produto foram desenvolvidos os creosotos fortificados (Lumsden, 1960; Hartford, 1973; Wilkinson, 1979; Lepage, 1986; Richardson, 1993).

\subsection{Ensaio de Apodrecimento Acelerado de Campo}

Em virtude da simplicidade, foi empregado o método-padrão sugerido pela IUFRO e descrito por Becker (1970). O método preconiza o emprego de estacas com dimensões de 50 × 5,0 x 2,5 cm, as quais devem ser de madeira de alburno.

As estacas utilizadas na pesquisa foram confeccionadas do alburno de cinco árvores de Eucalyptus grandis, provenientes de um povoamento com 14 anos de idade, localizado na Horta Nova, propriedade da Universidade Federal de Viçosa, no município de Viçosa-MG.

Em virtude da espessura do alburno nas árvores abatidas, empregaram-se corpos-de-prova de 50 x 5,0 x $2,0 \mathrm{~cm}$. As amostras foram acondicionadas por quatro meses a $25 \pm 1{ }^{\circ} \mathrm{C}$ e $65 \pm 5 \%$ de umidade relativa. Após o acondicionamento, mediram-se o volume e a massa das amostras.

As amostras foram tratadas pelo processo de célula cheia, em uma autoclave-piloto de $19,5 \mathrm{~cm}$ de diâmetro e 53,0 cm de comprimento. No tratamento das estacas, empregou-se um vácuo inicial de $200 \mathrm{~mm}$ de $\mathrm{Hg}$ por 5 minutos, aplicou-se o produto e a pressão foi elevada e mantida em $2 \mathrm{kgf} / \mathrm{cm}^{2}$ por 5 minutos. A seguir, liberouse a pressão, removeu-se o produto preservativo e aplicou-se um vácuo final de $100 \mathrm{~mm}$ de $\mathrm{Hg}$ por 2 minutos, para remoção do excesso de produto da superfície das estacas. Após tratamento, as estacas foram limpas com papel absorvente, pesadas e avaliada sua retenção.

A retenção ( $\mathrm{kg}$ de substância preservativa $/ \mathrm{m}^{3} \mathrm{de}$ madeira) foi determinada ao dividir a diferença de massa das amostras (antes e depois de tratadas) pelo seu volume inicial. As estacas foram empilhadas em local ventilado, assim permanecendo por duas semanas.

Os campos de apodrecimento foram instalados em Viçosa, Ponte Nova e Leopoldina, municípios da Zona da Mata de Minas Gerais. Nessas localidades, foram instaladas cinco amostras para cada tratamento (Quadro 1), distribuídas em blocos ao acaso. $\mathrm{O}$ ensaio foi inspecionado após 6, 12, 24, 37 e 48 meses da instalação. Na análise e avaliação da eficiência dos produtos preservativos empregados foram seguidas as recomendações do método da IUFRO, e classificou-se o estado de sanidade das estacas conforme o Quadro 2.

\subsection{Avaliação dos Resultados}

O desempenho das estacas foi avaliado pelo emprego de um delineamento em blocos casualizados, com arranjo fatorial, e utilizou-se a quantidade de estacas deterioradas, por índice de comportamento, para auxiliar nas discussões das análises estatísticas.

R. Árvore, Viçosa-MG, v.26, n.4, p.475-484, 2002 
Quadro 1 - Soluções preservativas preparadas com creosoto vegetal

Table 1 - Preservative solutions prepared with wood tar creosote

\begin{tabular}{|l|l|}
\hline Creosoto Vegetal & Tratamento/Solução Preservativa \\
\hline \multirow{3}{*}{1 - Creosoto vegetal bruto } & 1 - creosoto 1 puro \\
& $2-$ creosoto $1+3 \%$ de naftenato de cobre \\
& $3-$ creosoto $1+3 \%$ de naftenato de zinco \\
& $4-$ creosoto $1+3 \%$ de naftenato de cobalto \\
& $5-$ creosoto $1+2 \%$ de óxido de tributil-estanho (TBTO) \\
& $6-$ creosoto $1+2 \%$ de tribromofenato de tributil-estanho \\
& $7-$ creosoto $1+2 \%$ de pentaclorofenol \\
& $8-$ creosoto $1+0,4 \%$ de trióxido de arsênico \\
\hline \multirow{2}{*}{$2-$ Creosoto vegetal purificado } & 9 - creosoto 2 puro \\
& $10-$ creosoto $2+3 \%$ de naftenato de cobre \\
& $11-$ creosoto $2+3 \%$ de naftenato de zinco \\
& $12-$ creosoto $2+3 \%$ de naftenato de cobalto \\
& $13-$ creosoto $2+2 \%$ de oxido de tributil-estanho (TBTO) \\
& $14-$ creosoto $2+2 \%$ de tribromofenato de tributil-estanho \\
& $15-$ creosoto $2+2 \%$ de pentaclorofenol \\
& 16 - creosoto $2+0,4 \%$ de trióxido de arsênico \\
\hline \multirow{2}{*}{ Testemunha } & 17 - creosoto mineral \\
& 18 - madeira sem tratamento \\
\hline
\end{tabular}

Quadro 2 - Avaliação do ensaio de campo Table 2 - Field assay evaluation

\begin{tabular}{|l|c|c|}
\hline \multicolumn{1}{|c|}{ Estado de Sanidade } & Nota & Índice de Comportamento \\
\hline Sadio & 0 & 100 \\
Ataque superficial & 1 & 90 \\
Ataque moderado & 2 & 70 \\
Ataque intenso & 3 & 40 \\
Quebra & 4 & 0 \\
\hline
\end{tabular}

Para comparar a eficiência das soluções preparadas com creosoto vegetal com as testemunhas, analisaramse os seguintes fatores: tratamento, com 18 níveis; localidade, com 3 níveis; e a interação entre estes fatores.

$\mathrm{Na}$ análise do efeito da purificação do creosoto vegetal, os tratamentos, propostos no Quadro 1, foram agrupados em função dos produtos químicos utilizados para enriquecimento e analisados sem a presença das testemunhas. Neste caso, analisaram-se os seguintes fatores: solução preservativa, com 8 níveis; creosoto, com 2 níveis; localidade, com 3 níveis; e as interações entre estes fatores. $\mathrm{O}$ resultado desta análise é apresentado e discutido logo após as análises completas, em que todos os tratamentos foram analisados.

R. Árvore, Viçosa-MG, v.26, n. 4, p.475-484, 2002
Para permitir as análises, as notas atribuídas às estacas foram transformadas em raiz (nota $+0,5$ ). Esta transformação dos dados, sugerida por Steel \& Torrie (1980), foi necessária para permitir a análise de variância das notas. Na análise e avaliação dos ensaios empregouse o teste de Tukey, em nível de 5\% de probabilidade, para os fatores e as interações detectados como significativos pelo teste de $\mathrm{F}$.

\section{RESULTADOS E DISCUSSÃO}

As retenções médias $\left(\mathrm{kg} / \mathrm{m}^{3}\right)$ de preservativos para cada tratamento estão apresentadas no Quadro 3. Notase, neste quadro, que elas foram superiores ao mínimo preconizado pela norma NBR-8456 da ABNT (1973), que é de $130 \mathrm{~kg} / \mathrm{m}^{3}$ de madeira tratada. Esta é a retenção suficiente para garantir o bom desempenho de postes de Eucalyptus sp. tratados com creosoto mineral. Observa-se também que as variações entre as retenções médias, das soluções preparadas com o creosoto vegetal, foram pequenas, sendo a discrepância entre as retenções máxima e mínima de apenas $11,34 \mathrm{~kg} / \mathrm{m}^{3}$, portanto incapaz de influenciar os resultados dos ensaios. Esta afirmativa esta embasada em Cavalcante (1984). Este autor afirmou que os acréscimos em valores de retenção, acima do mínimo estipulado pela NBR-8456, não 
ocasionam ganhos significativos no comportamento do material tratado. Além disto, Jankowsky (1986 b), ao trabalhar com creosoto vegetal de três origens diferentes, não encontrou diferenças significativas para variações de $10,7 \mathrm{~kg} / \mathrm{m}^{3}$ para a madeira submetida ao ataque de fungos e de cupins, em ensaios de laboratório.

A quantidade de estacas deterioradas por índice de comportamento, para as avaliações efetuadas após 6, 12, 24,37 e 48 meses nos campos de apodrecimento instalados nas três localidades avaliadas, encontra-se no Quadro 3.

Até a presente avaliação, realizada após 48 meses de instalação do ensaio de campo (Quadro3), observou-se que $38,89 \%$ dos tratamentos atingiram sua vida útil média, que é $60 \%$ das estacas quebradas, conforme o citado por McLean (1952). O tratamento18 (estacas-testemunha, confeccionadas de alburno de E. grandis não-tratado) atingiu sua vida útil entre 12 e 24 meses, com $86,67 \%$ das estacas quebradas, e entre 24 e 37 meses ocorreu a quebra em $100 \%$ das estacas. O tratamento 5 (estacas tratadas com creosoto $1+$ TBTO) atingiu sua vida útil entre $24 \mathrm{e}$ 37 meses, com $66,67 \%$ das estacas quebradas, e na presente inspeção ocorreu a quebra em $86,67 \%$ das estacas. O tratamento 3 (estacas tratadas com o creosoto 1 + naftenato de zinco) apresentou $80 \%$ das estacas quebradas, tendo atingido sua vida útil média entre 37 e 48 meses. Os tratamentos 4, 9, 11 e 13 (estacas tratadas com creosoto $1+$ naftenato de cobalto, com creosoto 2 puro ou com creosoto $2+$ naftenato de zinco ou TBTO, respectivamente) atingiram sua vida útil média aos 48 meses.

Dentre as estacas tratadas com o creosoto de Eucalyptus spp., os tratamentos 15, 14, 7 e 2, respectivamente, estacas tratadas com creosoto $2+$ pentaclorofenol ou tribromofenato de tributil-estanho, com creosoto $1+$ pentaclorofenol ou naftenato de cobre, foram aqueles que melhor proteção conferiram às estacas, contudo sem atingir o desempenho do tratamento 17 (estacas tratadas com creosoto mineral).

Além do ataque de fungos, observou-se o ataque de cupins em várias estacas instaladas em Leopoldina. $\mathrm{O}$ ataque de cupins ocorreu em cinco estacas nos tratamentos 3 e 6 , em quatro nos tratamentos $1,5,8,11$ e 13, em três nos tratamentos 4,7 e 9, em duas nos tratamentos 2 , 1012 e 14 e em uma estaca nos tratamentos 15 e 16 . Em relação à inspeção realizada após 24 meses de instalação do ensaio (PAES et al., 1999), foi observado um aumento significativo na quantidade de estacas atacadas por cupins.
Como o creosoto vegetal demonstrou ser eficiente contra cupins subterrâneos do gênero Nasutitermes (Paes, 1997; Paes et al.,1998) e contra cupins de madeira seca da espécie Cryptotermes brevis (Jankowski, 1986 b), em testes de laboratório e na inspeção realizada após 12 meses de instalação do ensaio de campo, não foi observado ataque de cupins nas estacas tratadas, pois talvez a eficiência do creosoto vegetal tenha ficado comprometida, em virtude das reações químicas provocadas pelos efeitos da radiação solar, da perda de frações mais leves pela exposição ao calor e à ventilação e pela lixiviação provocada pelas chuvas, o que pode ter causado o envelhecimento das soluções preparadas como o creosoto vegetal.

Para avaliação dos efeitos dos tratamentos (Quadro 1) e das localidades, os resultados obtidos após 48 meses (Quadro 3) foram separados por localidades e procederam-se às análises estatísticas das notas atribuídas a cada estaca.

A análise de variância em que todos os tratamentos foram comparados acusou diferenças significativas, pelo teste de F, entre os tratamentos e as localidades, sendo o efeito interativo desses fatores não-significativo. O resultado do teste de médias aplicado aos efeitos que foram significativos é apresentado no Quadro 4.

Observa-se, nesse quadro, que o creosoto mineral (tratamento 17) proporcionou melhor proteção à madeira. Porém, dele não se diferiu o tratamento 15 (estacas tratadas com o creosoto $2+$ pentaclorofenol). Nota-se também que o tratamento 18 (estacas confeccionadas com madeira de $E$. grandis não-tratadas) apresentou o pior desempenho nos campos de apodrecimento. Além dos tratamentos 15 e 17 , apenas as estacas tratadas com o creosoto $1+$ tribromofenato de tributil-estanho ou pentaclorofenol, respectivamente, tratamentos $6 \mathrm{e} 7$, apresentaram desempenho superior ao da testemunha (tratamento 18). As soluções preservativas proporcionaram ganhos significativos na resistência das estacas, pois na inspeção realizada após 24 meses de instalação do ensaio de campo constatou-se que o tratamento 18 foi inferior aos demais, com $86,67 \%$ de estacas quebradas (Paes et al., 1999).

Como o tratamento 15 se assemelhou a vários outros, que depois de 48 meses apresentaram desempenho semelhante ao observado para a madeira não-tratada (tratamento 18), e também com base no Quadro 3, pode-se afirmar que o creosoto mineral (tratamento 17) proporcionou melhor desempenho dentre todos os tratamentos testados.

R. Árvore, Viçosa-MG, v.26, n.4, p.475-484, 2002 
Quadro 3 - Quantidade total de estacas deterioradas por índice de comportamento após 6, 12, 24, 37 e 48 meses de instalação dos três ensaios de campo

Table 3 - Total amount of decay stakes by index of condition after 6,12,24, 37 and 48 months on the three field-tests

\begin{tabular}{|c|c|c|c|c|c|c|}
\hline \multirow{2}{*}{$\begin{array}{l}\text { Tratamento } \\
\text { (Retenção) }\end{array}$} & \multirow{2}{*}{ Mês } & \multicolumn{5}{|c|}{ Classe de Índice de Comportamento } \\
\hline & & 100 & 90 & 70 & 40 & 0 \\
\hline $\begin{array}{c}1 \\
(147,25)\end{array}$ & $\begin{array}{r}6 \\
12 \\
24 \\
37 \\
48\end{array}$ & $\begin{array}{l}3 \\
1 \\
- \\
- \\
-\end{array}$ & $\begin{array}{c}12 \\
8 \\
4 \\
3 \\
1\end{array}$ & $\begin{array}{l}- \\
6 \\
4 \\
3 \\
2\end{array}$ & $\begin{array}{l}- \\
- \\
5 \\
2 \\
4\end{array}$ & $\begin{array}{l}- \\
- \\
2 \\
7 \\
8\end{array}$ \\
\hline $\begin{array}{c}2 \\
(157,99)\end{array}$ & $\begin{array}{r}6 \\
12 \\
24 \\
37 \\
48\end{array}$ & $\begin{array}{c}10 \\
4 \\
1 \\
- \\
-\end{array}$ & $\begin{array}{l}5 \\
9 \\
5 \\
3 \\
3\end{array}$ & $\begin{array}{l}- \\
2 \\
5 \\
5 \\
3\end{array}$ & $\begin{array}{l}- \\
- \\
3 \\
2 \\
2\end{array}$ & $\begin{array}{l}- \\
- \\
1 \\
5 \\
7\end{array}$ \\
\hline $\begin{array}{c}3 \\
(151,26)\end{array}$ & $\begin{array}{r}6 \\
12 \\
24 \\
37 \\
48\end{array}$ & $\begin{array}{l}9 \\
4 \\
1 \\
- \\
-\end{array}$ & $\begin{array}{l}6 \\
6 \\
7 \\
4 \\
1\end{array}$ & $\begin{array}{l}- \\
5 \\
2 \\
2 \\
-\end{array}$ & $\begin{array}{l}- \\
- \\
5 \\
3 \\
2\end{array}$ & $\begin{array}{c}- \\
- \\
- \\
6 \\
12\end{array}$ \\
\hline $\begin{array}{c}4 \\
(151,70)\end{array}$ & $\begin{array}{r}6 \\
12 \\
24 \\
37 \\
48 \\
\end{array}$ & $\begin{array}{c}12 \\
2 \\
- \\
- \\
- \\
\end{array}$ & $\begin{array}{c}3 \\
12 \\
7 \\
5 \\
2 \\
\end{array}$ & $\begin{array}{l}- \\
1 \\
5 \\
2 \\
4 \\
\end{array}$ & $\begin{array}{l}- \\
- \\
3 \\
3 \\
-\end{array}$ & $\begin{array}{l}- \\
- \\
- \\
5 \\
9\end{array}$ \\
\hline $\begin{array}{c}5 \\
(158,59)\end{array}$ & $\begin{array}{r}6 \\
12 \\
24 \\
37 \\
48 \\
\end{array}$ & $\begin{array}{c}12 \\
1 \\
1 \\
- \\
- \\
\end{array}$ & $\begin{array}{c}3 \\
12 \\
3 \\
- \\
- \\
\end{array}$ & $\begin{array}{l}- \\
2 \\
5 \\
4 \\
2 \\
\end{array}$ & $\begin{array}{l}- \\
- \\
4 \\
1 \\
- \\
\end{array}$ & $\begin{array}{c}- \\
- \\
2 \\
10 \\
13 \\
\end{array}$ \\
\hline $\begin{array}{c}6 \\
(155,94)\end{array}$ & $\begin{array}{r}6 \\
12 \\
24 \\
37 \\
48 \\
\end{array}$ & $\begin{array}{c}13 \\
6 \\
1 \\
- \\
- \\
\end{array}$ & $\begin{array}{c}2 \\
8 \\
10 \\
6 \\
3 \\
\end{array}$ & $\begin{array}{l}- \\
1 \\
- \\
3 \\
5\end{array}$ & $\begin{array}{l}- \\
- \\
3 \\
2 \\
1 \\
\end{array}$ & $\begin{array}{l}- \\
- \\
1 \\
4 \\
6\end{array}$ \\
\hline $\begin{array}{c}7 \\
(150,08)\end{array}$ & $\begin{array}{r}6 \\
12 \\
24 \\
37 \\
48 \\
\end{array}$ & $\begin{array}{c}12 \\
8 \\
4 \\
1 \\
- \\
\end{array}$ & $\begin{array}{l}3 \\
5 \\
5 \\
4 \\
4 \\
\end{array}$ & $\begin{array}{l}- \\
2 \\
5 \\
5 \\
5 \\
\end{array}$ & $\begin{array}{l}- \\
- \\
1 \\
2 \\
1\end{array}$ & $\begin{array}{l}- \\
- \\
- \\
3 \\
5\end{array}$ \\
\hline $\begin{array}{c}8 \\
(147,94)\end{array}$ & $\begin{array}{c}6 \\
12 \\
24 \\
37 \\
48 \\
\end{array}$ & $\begin{array}{l}9 \\
6 \\
1 \\
- \\
- \\
\end{array}$ & $\begin{array}{l}6 \\
7 \\
9 \\
6 \\
3 \\
\end{array}$ & $\begin{array}{l}- \\
2 \\
2 \\
1 \\
2 \\
\end{array}$ & $\begin{array}{l}- \\
- \\
3 \\
2 \\
2 \\
\end{array}$ & $\begin{array}{l}- \\
- \\
- \\
6 \\
8 \\
\end{array}$ \\
\hline $\begin{array}{c}9 \\
(155,22)\end{array}$ & $\begin{array}{c}6 \\
12 \\
24 \\
37 \\
48\end{array}$ & $\begin{array}{c}11 \\
5 \\
1 \\
- \\
-\end{array}$ & $\begin{array}{l}4 \\
8 \\
5 \\
3 \\
1\end{array}$ & $\begin{array}{l}- \\
2 \\
6 \\
6 \\
5\end{array}$ & $\begin{array}{l}- \\
- \\
3 \\
2 \\
-\end{array}$ & $\begin{array}{l}- \\
- \\
- \\
4 \\
9\end{array}$ \\
\hline
\end{tabular}


Quadro 3, cont.

Table 3, cont.

\begin{tabular}{|c|c|c|c|c|c|c|}
\hline \multirow{2}{*}{$\begin{array}{l}\text { Tratamento } \\
\text { (Retenção) }\end{array}$} & \multirow{2}{*}{ Mês } & \multicolumn{5}{|c|}{ Classe de Índice de Comportamento } \\
\hline & & 100 & 90 & 70 & 40 & 0 \\
\hline $\begin{array}{c}10 \\
(151,85)\end{array}$ & $\begin{array}{c}6 \\
12 \\
24 \\
37 \\
48\end{array}$ & $\begin{array}{c}13 \\
6 \\
3 \\
- \\
-\end{array}$ & $\begin{array}{l}2 \\
9 \\
6 \\
6 \\
-\end{array}$ & $\begin{array}{l}- \\
- \\
3 \\
2 \\
6\end{array}$ & $\begin{array}{l}- \\
- \\
3 \\
4 \\
3\end{array}$ & $\begin{array}{l}- \\
- \\
- \\
3 \\
6\end{array}$ \\
\hline $\begin{array}{c}11 \\
(150,53)\end{array}$ & $\begin{array}{c}6 \\
12 \\
24 \\
37 \\
48 \\
\end{array}$ & $\begin{array}{c}12 \\
3 \\
1 \\
- \\
-\end{array}$ & $\begin{array}{l}3 \\
9 \\
6 \\
3 \\
2 \\
\end{array}$ & $\begin{array}{l}- \\
3 \\
4 \\
4 \\
2\end{array}$ & $\begin{array}{l}- \\
- \\
4 \\
3 \\
2\end{array}$ & $\begin{array}{l} \\
- \\
- \\
5 \\
9\end{array}$ \\
\hline $\begin{array}{c}12 \\
(156,73)\end{array}$ & $\begin{array}{c}6 \\
12 \\
24 \\
37 \\
48 \\
\end{array}$ & $\begin{array}{c}11 \\
6 \\
1 \\
- \\
- \\
\end{array}$ & $\begin{array}{l}4 \\
8 \\
7 \\
4 \\
2 \\
\end{array}$ & $\begin{array}{l}- \\
1 \\
5 \\
7 \\
4 \\
\end{array}$ & $\begin{array}{l}- \\
- \\
2 \\
3 \\
4 \\
\end{array}$ & $\begin{array}{l}- \\
- \\
- \\
1 \\
5\end{array}$ \\
\hline $\begin{array}{c}13 \\
(148,00)\end{array}$ & $\begin{array}{c}6 \\
12 \\
24 \\
37 \\
48 \\
\end{array}$ & $\begin{array}{c}11 \\
6 \\
3 \\
- \\
- \\
\end{array}$ & $\begin{array}{l}4 \\
8 \\
4 \\
3 \\
1 \\
\end{array}$ & $\begin{array}{l}- \\
1 \\
6 \\
4 \\
4 \\
\end{array}$ & $\begin{array}{l}- \\
- \\
1 \\
4 \\
1 \\
\end{array}$ & $\begin{array}{l}- \\
- \\
1 \\
4 \\
9 \\
\end{array}$ \\
\hline $\begin{array}{c}14 \\
(150,44)\end{array}$ & $\begin{array}{c}6 \\
12 \\
24 \\
37 \\
48 \\
\end{array}$ & $\begin{array}{c}12 \\
5 \\
1 \\
- \\
- \\
\end{array}$ & $\begin{array}{l}3 \\
8 \\
6 \\
3 \\
1 \\
\end{array}$ & $\begin{array}{l}- \\
2 \\
7 \\
6 \\
5 \\
\end{array}$ & $\begin{array}{l}- \\
- \\
1 \\
3 \\
5 \\
\end{array}$ & $\begin{array}{l}- \\
- \\
- \\
3 \\
4\end{array}$ \\
\hline $\begin{array}{c}15 \\
(153,63)\end{array}$ & $\begin{array}{c}6 \\
12 \\
24 \\
37 \\
48 \\
\end{array}$ & $\begin{array}{c}12 \\
8 \\
4 \\
2 \\
1 \\
\end{array}$ & $\begin{array}{l}3 \\
5 \\
7 \\
6 \\
6 \\
\end{array}$ & $\begin{array}{l}- \\
2 \\
4 \\
5 \\
3 \\
\end{array}$ & $\begin{array}{l}- \\
- \\
- \\
1 \\
3 \\
\end{array}$ & $\begin{array}{l}- \\
- \\
- \\
1 \\
2 \\
\end{array}$ \\
\hline $\begin{array}{c}16 \\
(148,25)\end{array}$ & $\begin{array}{c}6 \\
12 \\
24 \\
37 \\
48 \\
\end{array}$ & $\begin{array}{l}8 \\
4 \\
1 \\
- \\
- \\
\end{array}$ & $\begin{array}{l}7 \\
9 \\
7 \\
6 \\
2 \\
\end{array}$ & $\begin{array}{l}- \\
2 \\
5 \\
2 \\
3 \\
\end{array}$ & $\begin{array}{l}- \\
- \\
2 \\
4 \\
4 \\
\end{array}$ & $\begin{array}{l}- \\
- \\
- \\
3 \\
6 \\
\end{array}$ \\
\hline $\begin{array}{c}17 \\
(146,40)\end{array}$ & $\begin{array}{c}6 \\
12 \\
24 \\
37 \\
48 \\
\end{array}$ & $\begin{array}{c}14 \\
11 \\
9 \\
5 \\
3 \\
\end{array}$ & $\begin{array}{c}1 \\
4 \\
6 \\
10 \\
10 \\
\end{array}$ & $\begin{array}{l}- \\
- \\
- \\
- \\
2 \\
\end{array}$ & $\begin{array}{l}- \\
- \\
- \\
- \\
- \\
\end{array}$ & $\begin{array}{l}- \\
- \\
- \\
- \\
-\end{array}$ \\
\hline $\begin{array}{c}18 \\
(0,00)\end{array}$ & $\begin{array}{c}6 \\
12 \\
24 \\
37 \\
48\end{array}$ & $\begin{array}{l}- \\
- \\
- \\
- \\
-\end{array}$ & $\begin{array}{l}7 \\
3 \\
- \\
- \\
-\end{array}$ & $\begin{array}{l}7 \\
5 \\
1 \\
- \\
-\end{array}$ & $\begin{array}{l}1 \\
4 \\
1 \\
- \\
-\end{array}$ & $\begin{array}{c}- \\
3 \\
13 \\
15 \\
15\end{array}$ \\
\hline
\end{tabular}


Quadro 4 - Comparações múltiplas entre médias, pelo teste de Tukey, para o índice de comportamento para todos os tratamentos após 48 meses de instalação do ensaio de campo

Table 4 - Multiple comparisons among averages, by the Tukey's test, for index of condition, for all treatments, after 48 months in field essay

\begin{tabular}{|c|c|c|c|}
\hline \multirow{2}{*}{ Tratamento } & \multicolumn{2}{|c|}{ Média } & \multirow{2}{*}{ Comparação } \\
\hline & Verdadeira & Transformada & \\
\hline $\begin{array}{r}18 \\
5 \\
3 \\
1 \\
13 \\
11 \\
9 \\
4 \\
10 \\
8 \\
16 \\
2 \\
14 \\
12 \\
6 \\
7 \\
15 \\
17 \\
\end{array}$ & $\begin{array}{l}4,00 \\
3,73 \\
3,67 \\
3,27 \\
3,20 \\
3,20 \\
3,13 \\
3,07 \\
3,00 \\
3,00 \\
2,93 \\
2,87 \\
2,80 \\
2,80 \\
2,67 \\
2,47 \\
1,93 \\
0,93 \\
\end{array}$ & $\begin{array}{r}2,12 \\
2,05 \\
2,03 \\
1,92 \\
1,90 \\
1,90 \\
1,88 \\
1,86 \\
1,86 \\
1,84 \\
1,83 \\
1,80 \\
1,80 \\
1,79 \\
1,75 \\
1,69 \\
1,51 \\
1,17 \\
\end{array}$ & $\begin{array}{l}a \\
a b \\
a b \\
a b \\
a b \\
a b \\
a b c \\
a b c \\
a b c \\
a b c \\
a b c \\
a b c \\
a b c \\
a b c \\
b c \\
b c \\
c d \\
d \\
\end{array}$ \\
\hline \multirow{2}{*}{ Localidade } & \multicolumn{2}{|c|}{ Média } & \multirow{2}{*}{ Comparação } \\
\hline & Verdadeira & Transformada & \\
\hline $\begin{array}{l}3 \text { - Leopoldina } \\
1 \text { - Viçosa } \\
2 \text { - Ponte Nova }\end{array}$ & $\begin{array}{l}3,28 \\
2,96 \\
2,54 \\
\end{array}$ & $\begin{array}{l}1,92 \\
1,83 \\
1,70 \\
\end{array}$ & $\begin{array}{l}\mathrm{a} \\
\mathrm{a} \\
\mathrm{b}\end{array}$ \\
\hline
\end{tabular}

As médias seguidas pela mesma letra não diferem entre si, em nível de 5\% de probabilidade.

Quanto ao efeito da localidade na deterioração provocada à madeira, notou-se que os organismos xilófagos presentes nos campos de Leopoldina e de Viçosa atacaram mais intensamente a madeira, quando comparados aos presentes no campo de Ponte Nova.

$\mathrm{Na}$ análise de variância em que as testemunhas (tratamentos 17 e 18) foram suprimidas, com o intuito de avaliar o efeito da purificação do creosoto vegetal, foram observadas, após 48 meses, diferenças significativas pelo teste de F, para o efeito da solução preservativa e da localidade e para a interação entre creosoto e localidade. O efeito da solução preservativa e da interação entre creosoto e localidade foi analisado, e as comparações múltiplas entre médias estão apresentadas no Quadro 5.

Nota-se (Quadro 5) que os tratamentos 7 e 15 (creosoto vegetal 1 ou 2 enriquecido com pentaclorofenol) têm proporcionado às estacas melhor desempenho no campo, sendo superior ao dos tratamentos 5 e 13; 3 e 11 ; e 1 e 9, respectivamente, madeira tratada com creosoto vegetal 1 ou 2 enriquecidos com TBTO ou com naftenato de zinco, e creosoto vegetal 1 ou 2 puros. Os demais tratamentos testados apresentaram comportamento intermediário.

Quanto ao efeito do creosoto vegetal no desempenho das estacas em cada localidade analisada (Quadro 5), nota-se que os creosotos 1 e 2 , respectivamente, creosoto vegetal purificado e não-purificado, proporcionaram desempenho semelhante para as estacas instaladas nas localidades de Viçosa e de Ponte Nova. Porém, para a localidade de Leopoldina, o creosoto 2 foi superior ao creosoto 1 . O efeito de cada localidade no desempenho das estacas tratadas demonstrou que o creosoto 1 apresentou pior desempenho que o creosoto 2 . 
Quadro 5 - Comparações múltiplas entre médias, pelo teste de Tukey, para o índice de comportamento, para o efeito da purificação do creosoto vegetal após 48 meses de instalação do ensaio de campo

Table 5 - Multiple comparisons among averages by the Tukey's test, for the purification of wood tar creosote, after 48 months in field essay

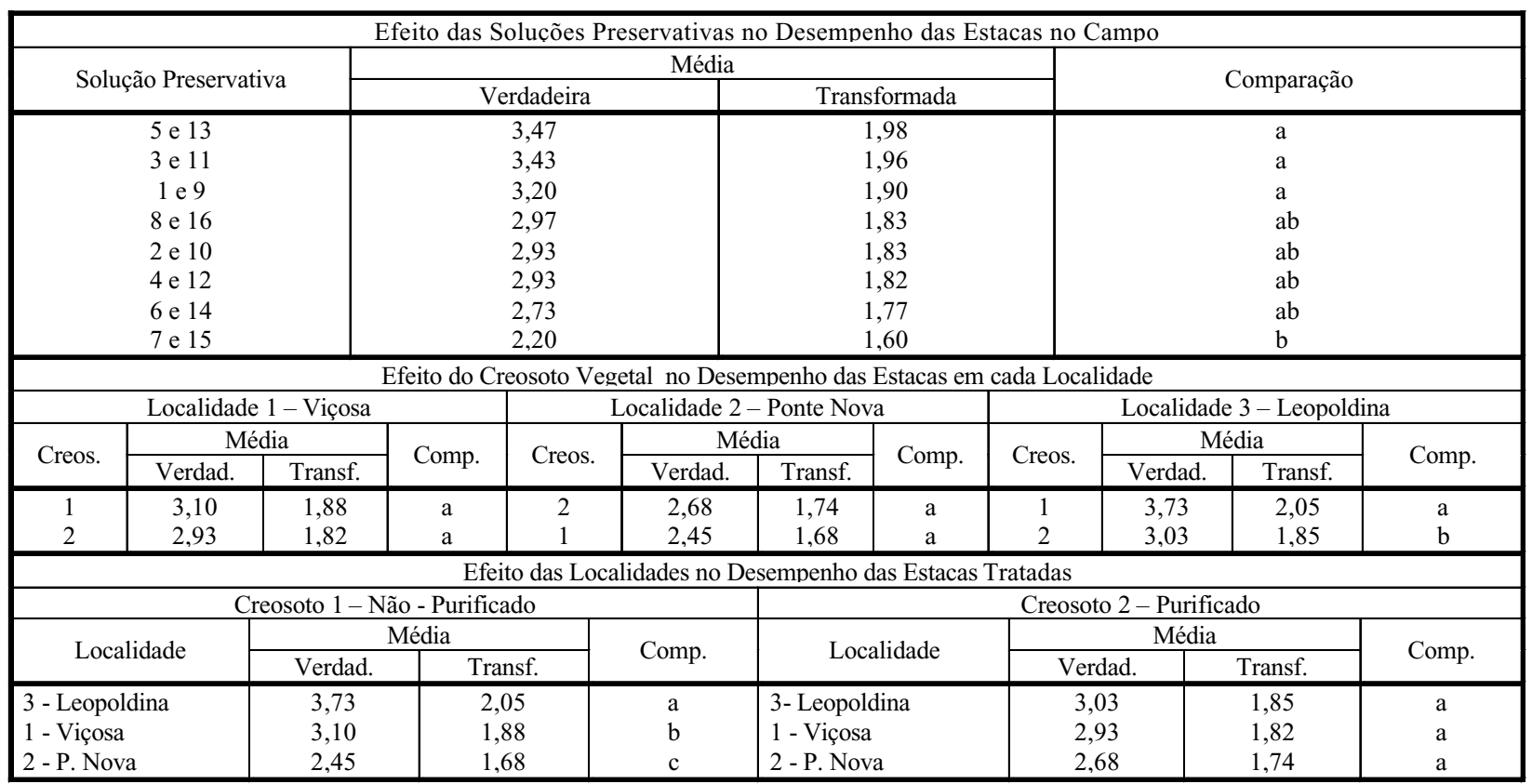

As médias seguidas pela mesma letra não diferem entre si, em nível de $5 \%$ de probabilidade.

Nota-se ainda que o creosoto 2 proporcionou desempenho semelhante, independentemente da localidade em que foram ensaiadas, enquanto o creosoto 1 apresentou desempenho diferenciado para as três localidades, sendo o pior desempenho na localidade de Leopoldina. A melhor proteção conferida às estacas pelo creosoto 2 é um bom indicativo da melhoria do creosoto vegetal como preservativo para madeiras, pois as soluções preparadas com este material apresentaram menor corrosão a chapas de aço, em ensaios de laboratório, e a parafusos em contato com a madeira tratada, em ensaio de campo (Paes, 1997).

\section{CONCLUSÕES}

Dentre as estaca tratadas, as impregnadas com o creosoto vegetal bruto enriquecido com TBTO apresentaram o pior desempenho no campo, tendo atingido sua vida útil entre 24 e 37 meses. Na presente inspeção, 86,67\% das estacas já se encontram totalmente deterioradas.

As estacas tratadas como o creosoto vegetal bruto enriquecido com naftenato de zinco atingiram a vida útil em serviço entre 37 e 48 meses, e atualmente está com $80 \%$ das estacas quebradas em virtude da ação dos xilófagos.

O creosoto vegetal bruto enriquecido com naftenato de cobalto, o creosoto vegetal purificado puro e esse produto enriquecido com naftenato de zinco ou com TBTO também não conferiram um bom desempenho às estacas, tendo essas atingido a vida útil aos 48 meses de instalação dos campos de apodrecimento.

As soluções enriquecidas com TBTO ou naftenato de zinco foram as que promoveram os piores desempenhos à madeira.

As soluções preparadas com o creosoto vegetal têm promovido melhorias no desempenho das estacas no campo, porém sem atingir o desempenho do creosoto mineral.

Os organismos xilófagos presentes nos solos de Viçosa e de Leopoldina foram os que promoveram maior deterioração às estacas. Em Leopoldina, além do ataque de fungo, ocorreu também o ataque de cupins, o que 
causou severo dano às estacas tratadas com os creosotos vegetais.

As soluções preparadas com o creosoto vegetal purificado, de modo geral, apresentaram melhor desempenho.

No atual estágio da pesquisa, não é possível estimar a vida útil média das estacas tratadas com as demais soluções preservativas, pois menos de $60 \%$ das estacas quebraram ao serem inspecionadas.

\section{REFERÊNCIAS BIBLIOGRÁFICAS}

ASSOCIAÇÃO BRASILEIRA DE NORMAS TÉCNICAS ABNT. NBR-8456 - Postes de eucalipto preservados para redes de distribuição de energia elétrica. Rio de Janeiro: 1973. $31 \mathrm{p}$.

BECKER, G. Método padrão sugerido pela IUFRO para ensaios de campo com estacas de madeira. Preservação de Madeira, v. 1, n. 4, p. 205-216, 1970.

BLEW, J. O.; CHAMPION, F. J. Preservative treatments of fence post and farm timber. Washington: USDA, Forest Service, Forest Products Lab., 1952. 33 p.

BLEW, J. O.; CHAMPION, F. J. Tratamiento preservador de postes de cerca e maderamen de granjas. 2.ed. México: Centro Regional de Ayuda Técnica, 1965. 45 p.

BLEW, J. O.; JOHNSTON, H. R. An international termite exposure test - twenty-second progress report. Washington: AWPA, 1956. $10 \mathrm{p}$.

CAVALCANTE, M. S. Retenção de preservativos para madeiras em diferentes usos. São Paulo: ABPM, 1984. 4 p. (Boletim ABPM, 19).

FINDLAY, W. P. K. Preservative substances. In: FINDLAY, W. P. K. (Ed.). Preservation of timber in the tropics. Dordrecht: Martinus Nijhoff/Dr. W. Junk Publishers, 1985. p. 59-74.

HARTFORD, W. H. Chemical and physical properties of wood preservatives and wood-preservative systems. In: NICHOLAS, D. D. (Ed.). Wood deterioration and its preservation by preservative treatments: preservative and preservative systems: Syracuse: Syracuse University, 1973. v. 2. p. 1-120.

HUNT, G. M.; GARRATT, G. A. Wood preservation. 3.ed. New York: Mc Graw Hill, 1967. 433 p.

HUNT, G. M.; SNYDER, T. E. An international termite exposure test. Nineteenth Progress Report. In: ANNUAL MEETING OF AWPA, 44., 1948, Washington.

Proceedings... Washington: AWPA, 1948. p. 392-406.

R. Árvore, Viçosa-MG, v.26, n. 4, p.475-484, 2002
JANKOWSKY, I. P. Os creosotos na preservação de madeiras. IPEF, n. 34, p. 5-14, 1986a.

JANKOWSKY, I. P. Potencialidade do creosoto de Eucalyptus spp., como preservativo para madeiras. São Paulo: Universidade de São Paulo, 1986. 159 p. Tese (Doutorado em Engenharia) - Universidade de São Paulo, 1986b.

LEPAGE, E. S. Preservativos e sistemas preservativos. In: LEPAGE, E. S. (Coord.). Manual de preservação de madeiras. São Paulo: Instituto de Pesquisa Tecnológica, 1986. v. 1. p. 279-342.

LUMSDEN, G. Q. Fortified wood preservative for southern pine poles. Forest Production Journal, v. 10, n. 9, p. 45662,1960 .

McLEAN, J. D. Preservative treatment of wood by pressure methods. Madison: USDA, Forest Service, Forest Products Laboratory, 1952. 160 p. (Agricultural Handbook, 40).

PAES, J. B. Efeitos da purificação e do enriquecimento do creosoto vegetal em suas propriedades preservativas. Viçosa: Universidade Federal de Viçosa, 1997. 143 p. Tese (Doutorado em Ciência Florestal) - Universidade Federal de Viçosa, 1997.

PAES, J. B. et al. Avaliação da eficiência do creosoto vegetal no tratamento de madeira após 24 meses de instalação do ensaio de campo. Revista Árvore, v. 23, n. 4, p. 463-472, 1999.

PAES, J. B. et al. Eficiência do creosoto vegetal contra cupins subterrâneos em testes de laboratório. Revista Árvore, v. 22, n. 1, p. 89-98, 1998.

RICHARDSON, B. A. Wood preservation. 2.ed. London: E \& FN SPON, 1993. 226 p.

STEEL, R. G. D.; TORRIE, J. H. Principles and procedures of statistics: a biometrical approach. 2.ed. New York: McGraw Hill, 1980. 633 p.

TIEMANN, H.D. Wood technology: constitution, properties and uses. 3.ed. New York: Pittmann Publishing Corporation, 1951. $396 \mathrm{p}$.

VAN GROENOV, H. B.; RISCHEN, H. W. L.; van den BERGE, J. Wood preservation during the last 50 years. 2.ed. Leiden: A. W. Sifthoff's vitgeversmaatschappij N. V., 1952. $318 \mathrm{p}$.

WENZL, H. F. J. The chemical technology of wood. New York: Academic, 1970. 692 p.

WILKINSON, J. G. Industrial timber preservation. London: The Rentokil Library/Associated Business, 1979. $532 \mathrm{p}$. 